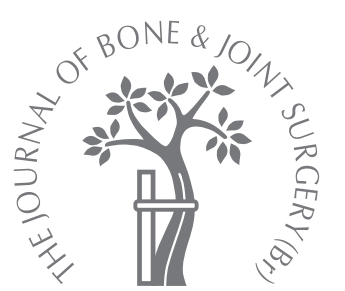

\title{
The pathology of frozen shoulder
}

G. C. R. Hand,

N. A. Athanasou,

T. Matthews,

A. J. Carr

From Nuffield

Department of

Othopaedic Surgery,

Oxford, England
E. C. R. Hand, FRCS(Trauma \& Orth), Fellow in Shoulder and Elbow Surgery

N. A. Athanasou, Professor of Pathology

T. Matthews, MBBS, BSc, FRCS(Eng), Henry Smith Research Fellow

Nuffield Orthopaedic Centre, Windmill Road, Headington,

Oxford OX3 7LD, UK.

A. J. Carr, ChM, FRCS, Nuffield Professor of Orthopaedic Surgery University of Oxford, Wellington Square, Oxford, OX1 2JD, UK.

Correspondence should be sent to Mr G. C. R. Hand at

Southampton University

Hospitals Trust, Southampton

General Hospital, Tremona

Road, Southampton, SO16

6YD, UK; e-mail:

mail@campbellhand.com

(C)2007 British Editorial Society of Bone and Joint Surgery doi:10.1302/0301-620X.89B7. $19097 \$ 2.00$

$J$ Bone Joint Surg $[\mathrm{Br}]$ 2007;89-B:928-32.

Received 4 January 2007;

Accepted 9 March 2007

\begin{abstract}
We treated 22 patients with a diagnosis of primary frozen shoulder resistant to conservative treatment by manipulation under anaesthetic and arthroscopic release of the rotator interval, at a mean time from onset of 15 months (3 to 36). Biopsies were taken from this site and histological and immunocytochemical analysis was performed to identify the types of cell present. The tissue was characterised by the presence of fibroblasts, proliferating fibroblasts and chronic inflammatory cells. The infiltrate of chronic inflammatory cells was predominantly made up of mast cells, with $T$ cells, B cells and macrophages also present.
\end{abstract}

The pathology of frozen shoulder includes a chronic inflammatory response with fibroblastic proliferation which may be immunomodulated.

Primary frozen shoulder is a common, severely debilitating condition with a prevalence of between $2 \%$ and $5 \% .^{1-3}$ It is frequently difficult to manage. The diagnosis is made on clinical grounds. A set of diagnostic criteria were initially described by Codman in $1934^{4}$ and still hold true today. They include pain in the shoulder which comes on slowly and is felt at the insertion of the deltoid, inability to sleep on the affected side, atrophy of the spinati, and little in the way of local tenderness. There is restriction of both active and passive movement, with painful and restricted elevation and external rotation. The pain is 'very trying', but the patient is able to continue with daily habits and routines. Radiographs of the shoulder appear normal. Stiffness may also occur after fracture or in association with joint diseases such as osteoarthritis (OA); this is referred to as a secondary frozen shoulder.

The pathology of frozen shoulder remains unclear, with information usually derived only from recalcitrant cases. Arthroscopy and open exploration of the frozen shoulder have increased our understanding of both the macroscopic and microscopic appearances. The pathology affects the glenohumeral capsular tissue and is particularly localised to the coracohumeral ligament in the rotator interval. $^{5-9}$ Analysis of this tissue has shown inflammatory changes, ${ }^{10,11}$ fibrosis ${ }^{12}$ and proliferative myelofibrosis. ${ }^{13}$ This process may be cytokine mediated. ${ }^{14,15}$ The aim of our study was to identify the cell type or types involved in the pathology of frozen shoulder, using new and previously unused immunocytochemical techniques and antibodies, in the hope that this may lead to earlier and more effective treatment of this often debilitating condition.

\section{Patients and Methods}

Biopsy material from the rotator interval was obtained at arthroscopy from 22 patients with a diagnosis of primary frozen shoulder and subjected to histological and immunocytochemical analysis.

The diagnosis of primary frozen shoulder was made according to Codman's criteria. ${ }^{4}$ All the patients were initially managed nonoperatively with intra-articular injection of local anaesthetic and steroid. There were 22 who failed to respond to conservative management and underwent a manipulation under anaesthesia, of whom ten were men and 12 were women, with a mean age of 53 years (41 to 66). The mean time from the onset of symptoms was 15 months (3 to 36 ). In 64\% (14 of 22) arthroscopy was undertaken less than 12 months from onset of the condition. All patients had symptomatic pain and stiffness at the time of biopsy. There were five diabetics, three of whom were non-insulin dependent.

The diagnosis of frozen shoulder was confirmed arthroscopically and a release of the tissue of the rotator interval performed. A biopsy was taken from this site and the material fixed in formalin and embedded in paraffin. The blocks were cut into $5 \mu \mathrm{m}$ sections 
Table I. Results for immunocytochemical and histological staining of biopsy material from the frozen shoulders

\begin{tabular}{|c|c|c|c|}
\hline Antibody & Cell type & Result ${ }^{*}$ & $\begin{array}{l}\text { Number of patients positive } \\
(\%)(\mathrm{n}=22)^{\dagger}\end{array}$ \\
\hline CD45 LCA LC $^{\ddagger}$ & Leukocytes & ++ & 11 of $19 \quad$ (58) \\
\hline CD3 & T cells & ++ & 11 of 19 \\
\hline CD20 & B cells & + & 1 of 19 \\
\hline CD68 & Macrophages & ++ & 10 of 19 \\
\hline$\alpha$ Smooth muscle action/Desmin & Myofibroblasts & + & 2 of 22 \\
\hline Lyve 1 & Lymphatic endothelium & +++ & 18 of 20 \\
\hline S100 & Neural tissue & ++ & 17 of 22 \\
\hline Vimentin & Fibroblasts & ++++ & 21 of 22 \\
\hline MIB1 & Proliferating cells & +++ & 20 of 22 \\
\hline Mast cell tryptase & Mast cells & ++ & 9 of $22(41)$ \\
\hline \multicolumn{4}{|l|}{ Histological stain } \\
\hline Toluidine blue & Mast cells & +++ & 13 of 21 \\
\hline Congo red & Amyloid & - & 22 of $22(100)$ \\
\hline
\end{tabular}

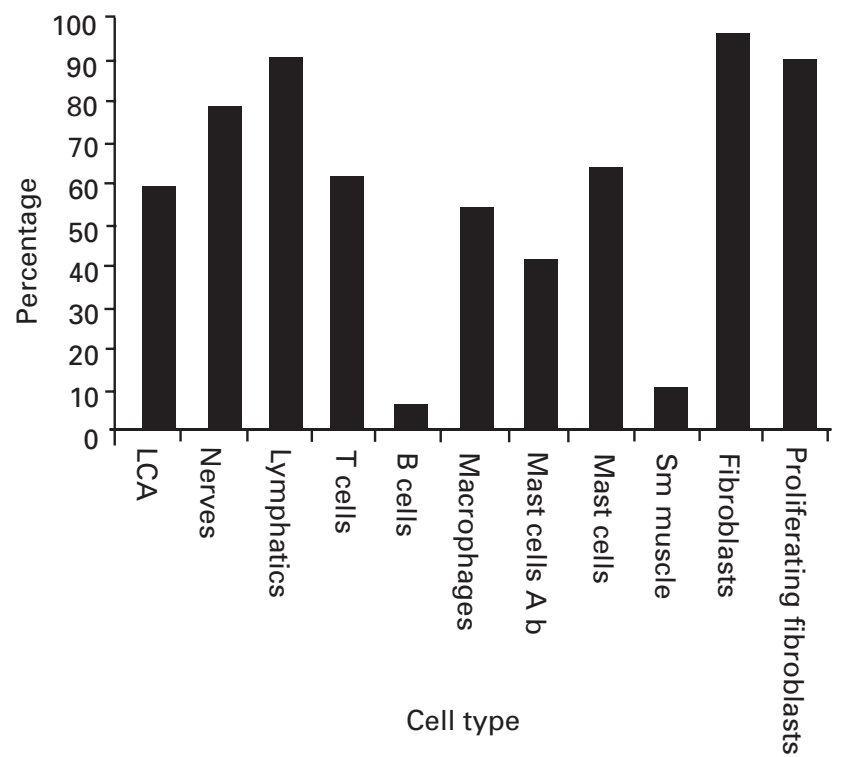

Fig. 1

Graph showing patients positive for cell type in frozen shoulder (\%) (LCA, leucocyte common antigen; Sm muscle, smooth muscle).

using a Leica RM2135 microtome (Leica Microsystems UK, Milton Keynes, United Kingdom), heat adhered on to Snowcoat X-tra pre-cleaned micro slides (Surgipath, Winnipeg, Canada) and stored at $37^{\circ} \mathrm{C}$.

The slides were stained with haematoxylin and eosin, toluidine blue and congo red for histological analysis. Immunocytochemical analysis was performed with antibodies directed against CD45 (Leukocyte common antigen (LCA)), CD3 ( $\mathrm{T}$ cells), CD20 (B cells), CD68 (macrophages), Lyve 1 (lymphatics), S100 (neural marker), PC10 and MIB1 (proliferative cell markers), vimentin, $\alpha$ smooth muscle actin and calponin (F-actin and tropomyosin).
The sections of mounted tissue were de-waxed in xylene and rehydrated through decreasing alcohol concentrations. Endogenous tissue peroxidase was blocked with a hydrogen peroxide solution. Antigen retrieval is antibody dependent and was performed according to the manufacturer's instructions (DakoCytomation DK-2600, Glostrup, Denmark). Two main techniques were used: heat-induced epitope retrieval and enzymatic pre-treatment with trypsin.

Visualisation was performed using the Autostrainer Plus (DakoCytomation) and the Chemate EnVision kit (DakoCytomation). This kit contains horseradish peroxidase conjugated secondary antibody on a polymer backbone, concentrated 3'3' diaminobenzidine chromogen and substrate buffer. After labelling with the primary antibody, the secondary antibody horseradish peroxidase-labelled polymer binds to the primary antibody. Bound horseradish peroxidase converts the diaminobenzidine into an insoluble brown precipitate visible on light microscopy. Standard laboratory positive control slides were used for all stains to confirm the success of the technique.

All the slides were examined under light microscopy and the presence of labelled cells was documented and tabulated. Absence of staining was documented as a negative result (-) and the presence of staining as a positive result $(+)$ using a scale based on the number of cells per high-power field $(\times 400),(+)=1$ to $4,(++) 5$ to $10,(+++)=>10,(++++)=>100$.

\section{Results}

Histological analysis of the biopsy material showed evidence of scattered chronic inflammation, mast cell infiltrate and an absence of amyloid (Table I and Fig. 1).

Immunocytochemistry confirmed an inflammatory infiltrate with significant positive staining for CD45 (LCA). Staining with CD3 (Fig. 2), CD20 (Fig. 3), CD68 (Fig. 4) and mast cell tryptase identified these cells to be predominantly mast cells (Fig. 5), macrophages T cells and B cells. Inflammatory cells were identified in 21 patients $(95 \%)$. 


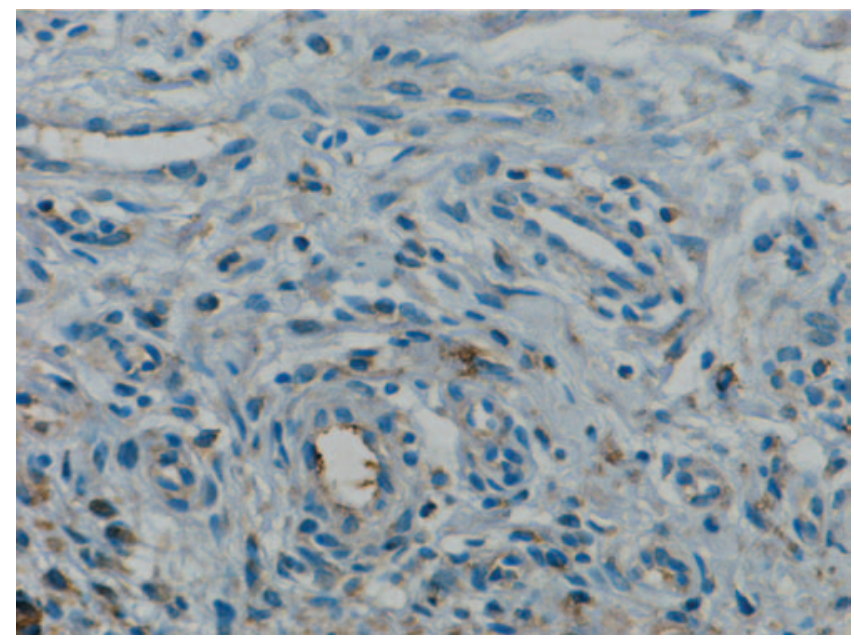

Fig. 2

CD3 T cells. Photomicrograph of immunocytochemistry, magnification $\times 400$.

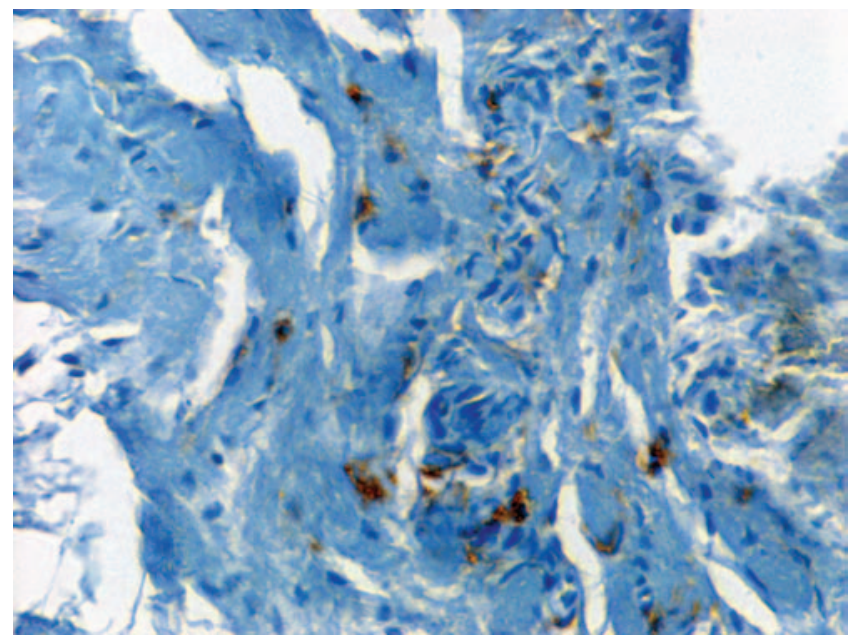

Fig. 4

CD68 macrophages. Photomicrograph of immunocytochemistry, magnification $\times 400$.

The CD34 antibodies stained strongly positive, identifying high vascularity in 15 patients $(68 \%)$.

Lyve 1 (Fig. 6) and S100 (Fig. 7) antibody staining was frequently positive, demonstrating the presence of lymphatic $(90 \%, 18$ of 20 , where on two occasions fragility of the tissue led to failure of the technique) and nervous tissue ( $77 \%, 17$ of 22), respectively. Staining with vimentin (Fig. 8), a fibroblast marker, showed the majority of the cell population to be fibroblasts; 95\% MIB1 (Ki 67) and proliferating cell nuclear antigen stained strongly, illustrating active proliferation of the fibroblasts. Desmin, $\alpha$ smooth-muscle action and calponin (smooth muscle cell markers) were

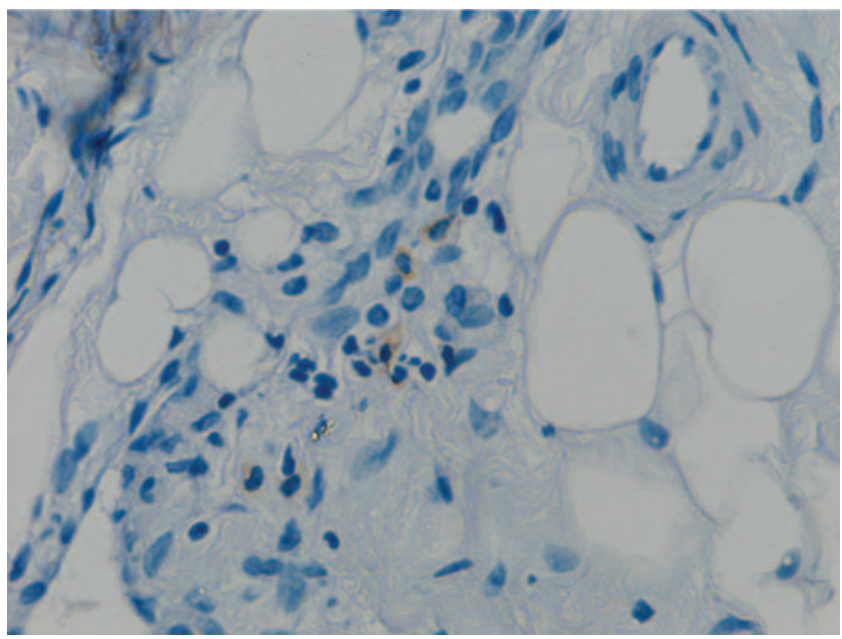

Fig. 3

CD20 B cells. Photomicrograph of immunocytochemistry, magnification $\times 400$.

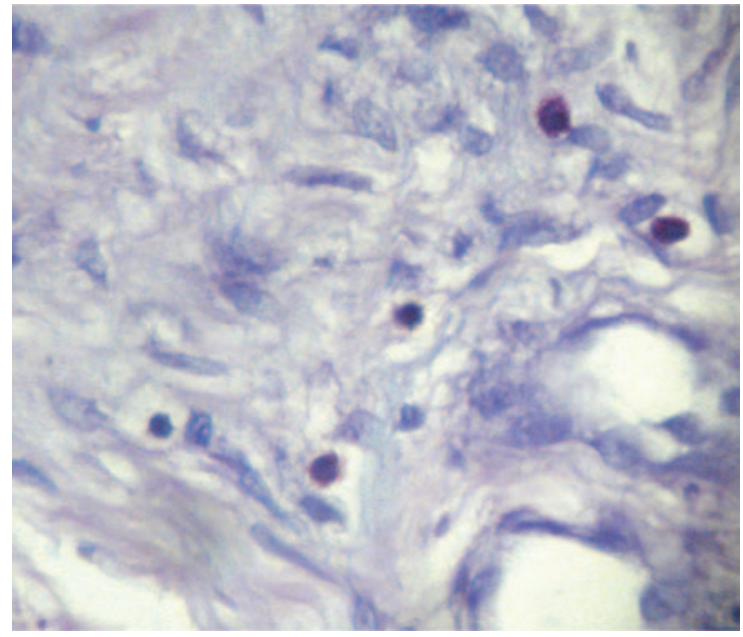

Fig. 5

Mast cells. Photomicrograph of toluidine blue staining, magnification $\times 400$.

usually stained negative outside the vessel wall, indicating very little evidence of myofibroblast cells (Fig. 9).

\section{Discussion}

Since the first description of this condition nearly 150 years ago, ${ }^{16}$ limited progress has been made in identifying the underlying mechanisms involved. ${ }^{1}$ Studies of cadavers and at open surgery and arthroscopy have identified the anatomical area predominantly involved in frozen shoulder to be the rotator interval, which contains the coracohumeral ligament. ${ }^{5,7-9,17-19}$ Biopsy material was therefore taken from this region for this study. 


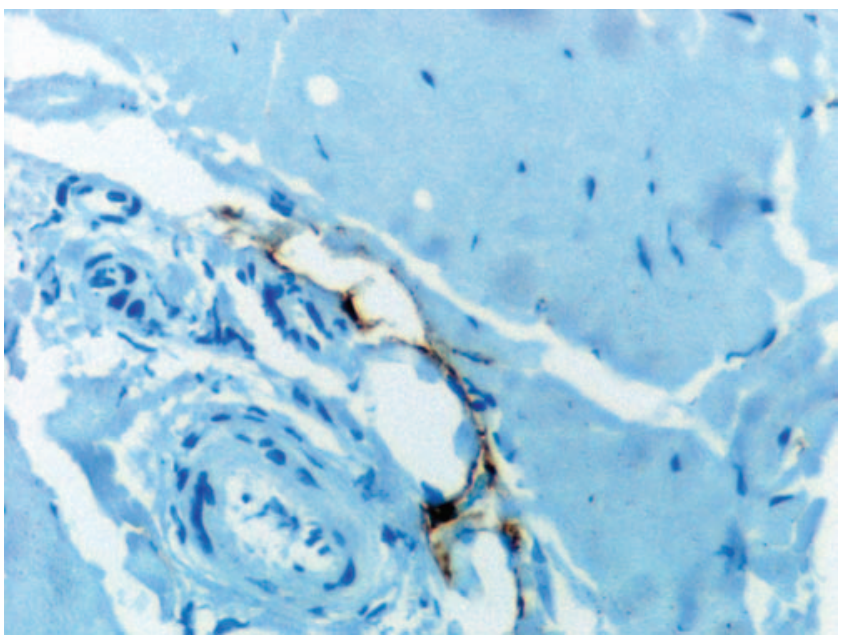

Fig. 6

Lyve 1 lymphatics. Photomicrograph of immunocytochemistry, magnification $\times 400$.

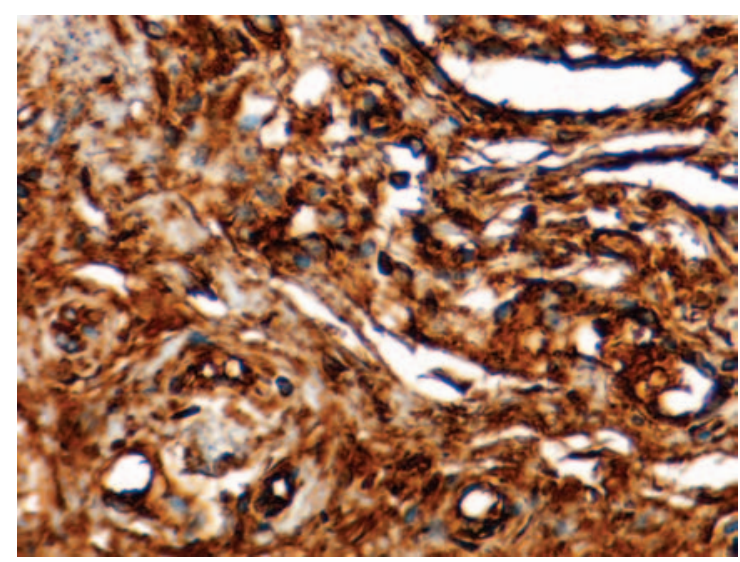

Fig. 8

Vimentin fibroblasts. Photomicrograph of immunocytochemistry, magnification $\times 400$.

A great deal of work has been directed at the microscopic pathology of frozen shoulder and three schools of thought have emerged: first, that it is an inflammatory process, ${ }^{10,11}$ second, a fibrotic process, $3,7,10,12,13,17,20$ and third, ${ }^{14}$ an inflammatory process with subsequent reactive capsular fibrosis.

Frozen shoulder is a painful, stiff condition which often responds to intra-articular steroids. Macroscopically the capsular tissue is thickened, inflammed and congested in appearance. ${ }^{10,11,13,17,19,21}$ These clinical and macroscopic features support the pathological findings of both inflammation and fibrosis. Characteristically, pain precedes stiffness in frozen shoulder, which suggests an evolution from inflammation to fibrosis. This study supports this theory by finding histological evidence of both an inflammatory cell infiltrate and fibrosis.

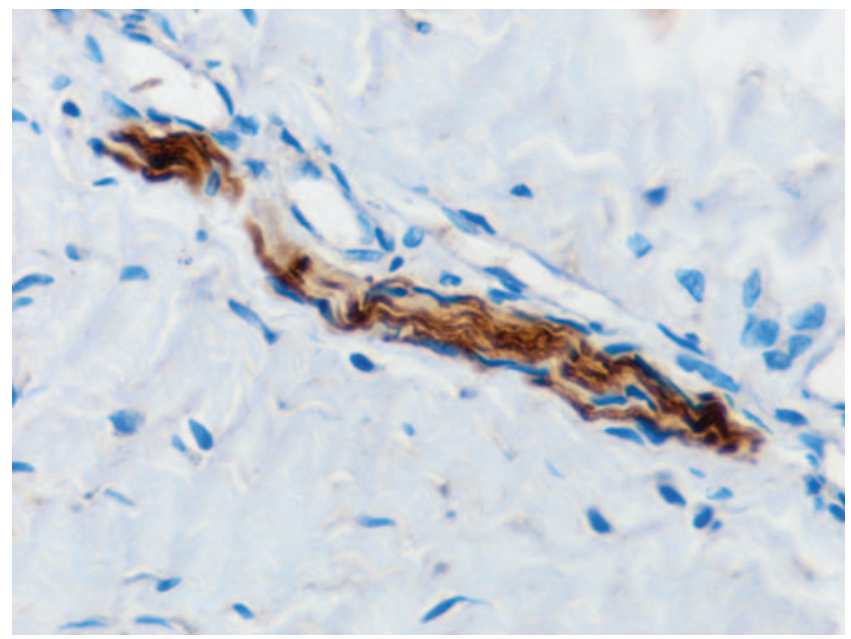

Fig. 7

S100 nerve tissue. Photomicrograph of immunocytochemistry, magnification $\times 400$.

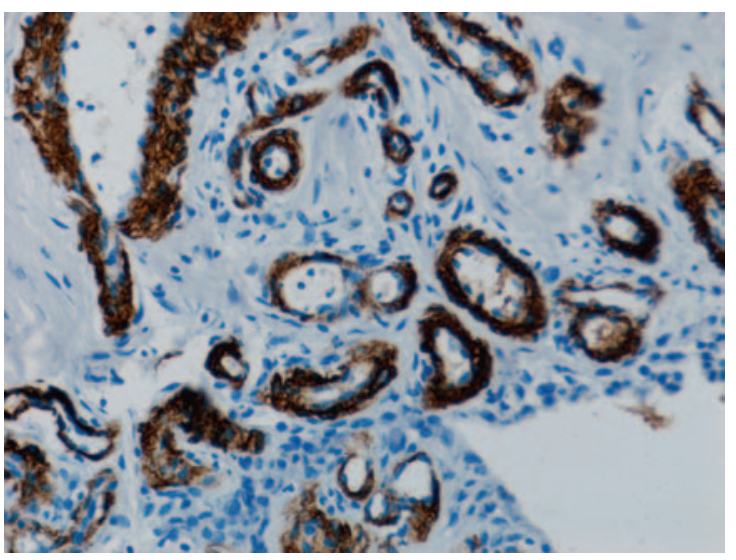

Fig. 9

ASMA vascular staining. Photomicrograph of immunocytochemistry, magnification $\times 400$.

Histological analysis showed a frequent scattered inflammatory infiltrate which was confirmed with immunocytochemistry using a variety of antibodies not previously used in the study of frozen shoulder. Analysis with CD3, CD20, CD68 and mast cell tryptase antibodies identified these cells to be predominantly mast cells, macrophages and $\mathrm{T}$ cells, confirming this to be a chronic inflammatory cell infiltrate. The presence of these immune system cells and of mast cells has not previously been seen in frozen shoulder. The CD34 antibodies stained strongly positive, identifying high vascularity resulting from angiogenesis. This vascularity is a characteristic macroscopic finding and is entirely consistent with the presence of chronic inflammation.

The presence of lymphatics (Lyve 1) in frozen shoulder is a new and previously undocumented finding, but may be 
anticipated in this inflammatory and fibrotic environment. Frequent positive staining for nerve cells (S100) is also a new observation and explains why frozen shoulder can be so painful.

Fibroblasts dominate the cell population and are actively proliferating, reinforcing previous observations that proliferative fibrosis is a characteristic finding. ${ }^{1,3,13}$

The pathology of frozen shoulder has been shown in other studies to be similar to that of Dupuytren's disease, ${ }^{1,13}$ but little evidence of a myofibroblast population, using the smooth muscle cell markers Desmin, asmoothmuscle action and calponin, was found in this study. The absence of myofibroblasts may indicate that the patients in this study were in the early, inflammatory stage of the condition, rather than the more chronic recalcitrant patients examined in other studies. ${ }^{1,13,14}$ No differences in cell population were noted as regards the longevity or severity of the symptoms in this study, which may be a result of the small sample size.

Mast cells regulate fibroblast proliferation both in vitro and in vivo. The presence of mast cells in the biopsies leads us to postulate that these chronic inflammatory cells may be the cellular intermediary to the fibroblast proliferation. The presence of $\mathrm{T}$ and $\mathrm{B}$ cells may mean that this mast cellmediated proliferative fibrosis is an immunomodulated response. Further investigation is required to evaluate these cellular interactions more clearly.

Differences in the cellular make-up were sought in the diabetic patients, but none were found, possibly as a result of the small sample size. Not every patient was stained with every antibody, as certain antibodies were interchangeable, such as proliferating cell nuclear antigen and MIB1 and $\alpha$ smooth-muscle actin and Desmin. In certain patients tissue failure during the enzymatic or heat treatment process of antibody retrieval occurred with inadequate residual tissue precluding retesting in these patients. This explains the apparent disparity of number for some antibodies in Table I.

In conclusion, arthroscope biopsy material from the rotator interval in patients with frozen shoulder revealed immunocytochemical evidence of both chronic inflammation and proliferative fibrosis, supporting the theory that this is both a chronic inflammatory and a fibrotic condition. Together with the presence of high vascularity and nerve tissue, this inflammation and fibrosis explains why frozen shoulder is such a painful and stiff condition. The presence of $\mathrm{T}$ and $\mathrm{B}$ cells suggests that the pathology may be immunomodulated. Mast cells, which are known to be involved in regulating fibroblast proliferation, may be the cellular intermediary between the chronic inflammation and fibrosis.

No benefits in any form have been received or will be received from a commercial party related directly or indirectly to the subject of this article.

\section{References}

1. Bunker TD. Frozen shoulder: unravelling the enigma. Ann $R$ Coll Surg Engl 1997;79:210-13

2. Bridgman J. Periarthritis of the shoulder and diabetes mellitus. Ann Rheum Dis 1972;31:69-71.

3. Hannafin J, Chiaia T. Adhesive capsulitis: a treatment approach. Clin Orthop 2000;372:95-109.

4. Codman E. Rupture of the supraspinatus tendon and other lesions in or about the subacromial bursa I. In: The shoulder. Boston: Thomas Todd, 1934.

5. Neer C, Satterlee C, Dalsey R, Flatow E. The anatomy and potential effects of contracture of the coracohumeral ligament. Clin Orthop 1992;280:182-5.

6. Ogilvie-Harris D, Biggs D, Fitsialos D, Mackay M. The resistant frozen shoulder: manipulation versus arthroscopic release. Clin Orthop 1995;319:238-48.

7. Ozaki J, Nakagawa Y, Sakurai G, Tamai S. Recalcitrant chronic adhesive capsulitis of the shoulder: role of contracture of the coracohumeral ligament and rotator interval in pathogenesis and treatment. J Bone Joint Surg [Am] 1989;71-A:1511-15.

8. Uitvlugt G, Detrisac DA, Johnson LL, Austin MD, Johnson C. Arthroscopic observations before and after manipulation of frozen shoulder. Arthroscopy 1993;9:181-5.

9. Wiley AM. Arthroscopic appearance of frozen shoulder. Arthroscopy 1991;7:138-43.

10. Neviaser J. Adhesive capsulitis of the shoulder: a study of the pathological findings in periarthritis of the shoulder. J Bone Joint Surg 1945;27:211-22.

11. Simmonds FA. Shoulder pain: with particular reference to frozen shoulder. J Bone Joint Surg [Br] 1949;31-B:426-32.

12. Lundberg BJ. The frozen shoulder: clinical and radiographical observations: the effect of manipulation under general anesthesia: structure and glycosaminoglycan content of the joint capsule: local bone metabolism. Acta Orthop Scand Suppl 1969;119:1-59.

13. Bunker T, Anthony P. The pathology of frozen shoulder: a Dupuytren-like disease. $J$ Bone Joint Surg [Br] 1995;77-B:677-83.

14. Bunker T, Reilly J, Baird K, Hamblen D. Expression of growth factors, cytokines and matrix metalloproteinases in frozen shoulder. J Bone Joint Surg [Br] 2000;82B:768-73.

15. Hutchinson J, Tierney G, Parsons S, Davis T. Dupuytren's disease and frozen shoulder induced by treatment with a matrix metalloproteinase inhibitor. J Bone Joint Surg [Br] 1998;80-B:907-8.

16. Duplay $\mathbf{S}$. De la peri-arthrite scapulo-humerale et des raideurs de l'epaule qui en sont la consequence. Arch Gen Med 1872;20:513-14.

17. DePalma A. Loss of scapulohomeral motion (frozen shoulder). Ann Surg 1952;135:193-204.

18. Bunker T, Fagas K, Deferme A. Arthroscopy and manipulation in frozen shoulder. $J$ Bone Joint Surg [Br] 1994;76-B(Suppl 1):53.

19. Ogilvie-Harris DJ, Wiley AM. Arthroscopic surgery of the shoulder: a general appraisal. J Bone Joint Surg [Br] 1986;68-B:201-7.

20. Kay NR, Slater DN. Fibromatoses and diabetes mellitus. Lancet 1981;2:303.

21. Quigley T. Checkrein shoulder: a type of frozen shoulder; diagnosis and treatment by manipulation and ACTH or cortisone. N Eng/ J Med 1954;250:188-92. 